organizations and individuals. At the request of Dr. J. H. Dellinger, for example, special solar observations were made at Mount Wilson Observatory at times when fade-outs were expected, to see if any visible solar effect could be associated with them, while an examination of old spectroheliograms immediately revealed the fact that a number of fade-outs already recorded had been accompanied by bright chromospheric eruptions. But perhaps the first really striking example of these interrelated phenomena occurred on April 8, 1936, when a very intense solar flare photographed at Mount Wilson was found to occur simultaneously with a widespread radio fade-out and the characteristic magnetic variation. As the solar activity has increased in recent years, many more examples of such correlations have been noticed.

To the student of the ionosphere, the temporary abnormal absorption of radio-waves during a fade-out is a phenomenon of great interest. When the disturbance is not too severe, and weak echoes can still be received, it is generally found that the height of reflection is not materially altered. The fade-out must thus be due, as Mögel suggested, to increased ionization at levels below those normally responsible for the reflection of medium and short radio waves. Such increased electron content in what was identified many years ago as Region $D$ would be expected to have three effects. It would temporarily increase the conductivity of the lower ionosphere for the overhead currents which cause the daily magnetic variations, and so account for the observed magnetic disturbance. It would increase the normal Region $D$ attenuation of radio waves passing through it and so explain the occurrence of the short and medium wave fadeout. At the same time, however, it would increase the reflection coefficient of Region $D$ for the very long waves which are deviated by its lower boundary. Such enhanced reflection of very long waves on the occasion of a short-wave fade-out was first noted by $R$. Bureau in his study of the propagational characteristics of atmospherics.

There can be little doubt that the enhanced ionization in Region $D$ during a solar flare is electronic in character, and that the exaggerated attenuating properties of this region as a radio transmission medium is due to the high frequency with which the electrons collide with the neutral molecules. Since the attenuating stratum is produced at a low level, the atmospheric absorption coefficient of the solar photons responsible must be relatively high. Possibly the electrons in question are liberated by photo-detachment from the negative ions which we suspect are present in large numbers during the daytime in Region $D$.

\title{
Archæological Sequence in North-West Honduras
}

$\mathrm{D}^{2}$ URING 1936 a joint archæological expedition of the Smithsonian Institution and Harvard University excavated a number of sites in the Departments of Cortes, Yoro and Santa Barbara in north-west Honduras. The expedition, which was in the nature of an archæological reconnaissance rather than a systematic exploration, had as its objective in part the extension of the explora. tory work carried out by Dr. W. D. Strong in north-eastern Honduras on behalf of the Smithsonian Institution in 1933, in part, and more immediately, to carry further the work of Byron D. Gordon (1895-97) and of the late Mrs. Dorothy H. Popenoe (1928-29). Mrs. Popenoe's pioneer work at Playa de los Muertos, where Gordon also excavated, in affording valuable and much-needed evidence of the stratigraphical relations of early cultures in this region, had opened up new vistas in the study of the archæology of Honduras. This evidence it was the purpose of the expedition to test and extend.

A detailed report of the results of the excavations of 1936 is in course of preparation; but as the mass of material precludes early publication, a preliminary report has been prepared by Dr. Strong, the senior member of the expedition, and his colleagues, in which an account is given of the major results emerging from the investigation.*

The sites investigated lie in what may be termed the drainage area of the Ulua River (including the Chamelecon River, which formerly drained into it) north-eastward from Lake Yojoa. The environmental conditions of this region belong to two types. On one hand are the broad alluvial valleys of the lower Ulua and Comayagua Rivers with dense rain forests; on the other hand are the elevated mountain valleys with clear flowing streams, in which the rain forest is limited to the border of the stream or, in the Lake Yojoa area, of the lake, while raised plateaux with oak and pine afford a background.

The sites examined are distributed geographic. ally in three groups : the Chamelecon group, of which Naco is the most extensive, the Ulua and Comayagua group, of which Playa de los Muertos

* Preliminary Report on the Smithsonian Institution-Harvard University Archæological Expedition to North-Western Honduras, 1936. By William Duncan Strong, Alfred Kidder II, and A. J. 1936. Brel Paul, Jr. Smithsonian Miscell. Collect., 97, 1, 1938. Pp. 129 Drexel Paul,
+14 plates. 
is the most important and for the early culture the type, and the Lake Yojoa group. This last includes only the northern shore of the lake, where is situated the most southerly ancient Mayan settlement. The reconnaissance thus covered the northern half of a natural transition area between the Pacific highland and the Atlantic lowland regions. At this point occurs one of the easiest passages across the central American isthmus from Tehuantepec to Panama, a factor of considerable archæological and historical importance.

Characteristically the sites are found either in the alluvium of the broad lower river valleys, or on the banks of the streams of the elevated valleys. Hence, while in the latter, mounds affording evidence of habitation sites, sometimes with burials added, are accessible to excavation, in the alluvial valleys, owing to the depth of the river silt, the investigation was most readily carried out by the examination of cultural deposits in the steep river banks exposed by the action of water.

At the time of the Spanish conquest, it would appear from early documentary and linguistic evidence, this part of Central America was occupied by Jicaque and Lenca-speaking peoples; but various Nahuatl-speaking (Aztecan) pueblos existed along what would seem to have been trade routes extending into this region from southern Mexico and the Pipil (Nahuatl) territory in Salvador. One such line of settlement crosses the Chamelecon near Naco and extends east to a short distance south of Trujillo. West of the Ulua there were groups of Mayan people, their influence also extending well into Lenca territory. The region, in fact, was a contact area, in which advanced Nahuatl and Mayan peoples impinged from the west upon less-advanced peoples to the east, whose linguistic affinities were with the south, and ultimately centred, possibly through the Chibchan stock, in northern South America. The archæological data now made available bear out this evidence of contact.

The artefacts obtained were predominantly ceramic-monochrome and polychrome painted ware. There was also a large number of pottery figurines in human and animal form, some of which are whistles, or had been attached to whistles. Artefacts of other material are, comparatively speaking, rare. Obsidian flakes are ubiquitous, but nowhere in large numbers. Knife blades, one projectile point and a few small celts were found. Stone polishers, pestles of large size, hammer-stones and broken metates, with a few beads of jade, jadeite, and other material occurred on various sites. Stone statues, much mutilated, are found in the Lake Yojoa area, where the sites are particularly rich in painted pottery and have been a prolific hunting ground for collectors. One specimen only of metal was found, a small fish-hook of copper from Las Flores Bolsa in the Ulua area. Charcoal, with hearths or fire-pits, is found on the floors of habitation sites, while burnt clay shows the impression of wattle and daub. The evidence of the numerous animal bones in the early culture of Playa de los Muertos points to a hunting people. Human skeletal remains from the numerous burials were in too bad a condition to provide much, if any, material of evidential value.

The excavations revealed a striking general resemblance in the stratification and contents of the deposits. Two distinct cultural horizons are separated by a period of sterility. The upper cultural level, marked by the occurrence of potsherds, begins on the stratified sites other than mounds at a depth below the surface of usually from forty to eighty centimetres, but sometimes more. It is characterized by two distinct classes of pottery, painted and a coarse domestic ware. On the painted pottery the decorative designs are either conventionalized animal or human forms, or geometric. They are of various colours, red, black, white, purple and sometimes blue on a background or slip of white, black, orange, buff or yellow. This ware is polished, some to a high degree. In some instances incised ornament also appears. On most, if not all of the sites, however, the second class or domestic ware predominates. This is normally a monochrome varying from a deep or brick red to grey or black; but a considerable number of sherds show crude linear designs in brown, deep red, or black.

The upper cultural level is superimposed on a sterile level of a sand and/or clay extending from approximately two to as much as four metres down. On certain sites a cultural horizon appears below the sterile deposits. It belongs to an earlier culture, and at Playa de los Muertos comprises from the four- to the six-metre level. The distinguishing feature of this culture is a form of pottery falling into a number of types or classes according to surface finish and decoration. The ware is found both with slip and without, and is mostly highly polished. One class, however, is a painted ware, black and red, or red and buff, and rarely a white slip with red lines. Not only is this painted pottery rare, but also it is highly variable, and has an experimental appearance. Certain finds suggest that Usulatan ware, such as is found in Salvador, "the earliest painted pottery found in Central America", forms a part of this early cultural complex. At Los Narranjos on Lake Yojoa occurs what is apparently an early form of the Playa de los Muertos early culture. It shows a very primitive type of pottery ; but its chronological relations are not yet definitely established. 
The main significance of these results lies not so much in the character of the finds on individual sites, as in the light thrown as a whole on the cultural sequences and affinities of north-western Honduras, and ultimately as a contribution towards the solution of the archæological problem of Central America, more especially in the matter of cultural and ethnic origins.

In determining the sequence and chronological relation of the cultures revealed by the results of this archæological reconnaissance, a point of departure is afforded by the excavations at Naco on the Chamelecon River, an important native settlement, also occupied for long by the Spaniards. Here in association with evidence of Late Nahuatl influence and a painted pottery culture were found two pieces of European pottery, of which, if one may have been a later intrusion, the other was probably contemporary with the early Spanish occupation.

From this point the cultures determined may be arranged in a chronological sequence as follows. First in the upper cultural level comes the Ulua Polychrome, comprising the domestic monochrome and two (or three) classes of painted ware, of which one, showing conventionalized human and animal forms, both from the character of the decorative motifs and the form of the vessels, is undoubtedly of Mayan derivation; and with this is the class, or classes, termed Bold Geometric and Bold Animalistic, the latter from Lake Yojoa, in which certain animal forms appear, but nevertheless to be associated closely with Bold Geometric. In both the Mayoid and the Geometric and Animalistic classes there is evidence of a lower and an upper type, indicated by a development from a more naturalistic to a more highly conventionalized style, in which animal forms found in early Geometric disappear. The Mayoid pottery occurs in such quantity as to justify the inference that it is the product not merely of Mayan influence but also of an actual association of Mayan settlers with the makers of the Geometric and Animalistic classes, each group pursuing its own tradition. The Geometric of the Ulua River is attributed to the Jicaque, the Animalistic of Lake Yojoa to the related Lenca.

As connecting links between the Ulua Poly. chrome and the earlier culture of the lower level of Playa de los Muertos are placed tentatively the Ulua Bichrome from Santa Rita and the early painted ware, Playa de los Muertos Bichrome, between which there would appear to be some evidence of relation. The occurrence of Usulatan ware in this level at Santa Rita is a link with Salvador, while the painted ware of Playa de los Muertos is referred to early levels at Uaxactun. The early Playa de los Muertos culture from the lower level on this site, which precedes the sterile deposits, may itself be preceded by the apparently primitive Monochrome from Lake Yojoa-a point still to be determined.

As regards the absolute chronology of this series of cultures, it is suggested, not without reason, that the Ulua Polychrome represents a development which took place after the fall of Copan, where the dated monuments, according to one computation, come to an end at A.D. 800. The Mayan element in north-western Honduras, on this argument, would represent settlements made on the dispersal which followed the fall of the Mayan Old Empire.

\section{Obituary Notices}

\section{Mr. A. J. Greenaway}

$\mathbf{J}^{\mathrm{o}}$ OHN GREENAWAY, for so he was known to his numerous friends, died after a long illness at Mill Hill on August 25. He was born at Islington on July 12, 1852, the youngest of four children and only son of John Greenaway (1816-90), well-known as a wood engraver and draughtsman from whom that great artist, Kate Greenaway (1846-1901)-the greatest and closest friend among many her brother ever possessed-derived her artistic inspiration.

After his early education at a local private school, Greenaway was apprenticed to his father, but later by his own wish he was allowed to study chemistry and entered the Royal College of Chemistry in Oxford Street, and was appointed demonstrator under Sir Edward Frankland when the College was transferred to South Kensington. Among his pupils during that period (1872-81) were the late Profs. W. H. and A. G. Perkin, with whom Greenaway maintained lifelong and intimate friendships. In 1880, Greenaway became an abstractor for the Chemical Society, beginning an editorial connexion which lasted until his retirement in 1924. In 1885, he was appointed sub-editor in charge of the Abstracts, and after the death of his friend, Dr. J. C. Cain, in 1921, he became editor.

During the early part of his work for the Chemical Society, Greenaway lived with his sister, Kate, in the house at Frognal, Hampstead, which had been built for her. After her death, he went to live at The Orchard, Chertsey, which was owned by Miss Ethel Boyce, a well-known musician. Through most of his life, Greenaway knew intimately great artists and musicians, particularly friends of his sister. 